\title{
VENEREAL DISEASE AND PROSTITUTION IN THE REPORTS OF THE POOR LAW COMMISSIONERS, 1834-1850*
}

BY

\section{A. FESSLER}

After the passing of the Poor Law Amendment Act in 1834, those who administered the poor law, i.e., the Guardians, Relieving Officers, Masters of the Workhouses, and the Poor Law Commissioners who constituted the supreme authority, had two distinct reasons for dealing with the problems of venereal disease and of prostitution.

First, according to the Elizabethan Act of 1601 which still formed the basis of the poor law, the sick poor had to be relieved. Considering the lack of treatment facilities for persons suffering from venereal disease (general infirmaries as a rule refused to admit them and lock-hospitals existed only in a few of the larger towns), there can be no doubt that a venereal infection must sometimes have caused destitution.

Second, the execution of the poor law had always been closely connected with that of the vagrancy acts, and prostitutes, who formed the main source of infection, were one of many groups commonly classed as vagrants. The governor of the House of Correction in Brixton, when asked by the Royal Commission (1832-1834) which preceded the Amendment Act to classify the females admitted to the Vagrants Ward, classified them as

felons, misdemeanants, idle and disorderly women which include prostitutes and lewd women ${ }^{1}$.

The reports of the Royal Commission and the Annual Reports of the Poor Law Commission (later the Poor Law Board) $\dagger$ contain several references to venereal disease and prostitution. It is of interest to record the more important of these references as a reflection of the official attitude towards these two problems in that period.

Segregation of the workhouse inmates according to their character had been one of the principal aims of the Poor Law Commissioners. Lack of

\footnotetext{
* Received for publication May 30, 1951.

† From 1848 onwards, the reports were presezted by the Poor Law Bcard.
}

accommodation made rigid separation impossible, even in the larger workhouses, and in spite of numerous orders and circulars "mixed" workhouses were still common in the first half of the 19th century, and the conditions prevailing in them aroused the indignation of contemporary critics from the beginning of the century onwards. J. Middleton (1807) described the crowded workhouses in Middlesex as

sinks of vice, for in them the old and the young, the healthy and those afflicted with loathsome diseases, the necessitous and the abandoned are all mixed in one home or perhaps in one room.

The report of $1835^{2}$ contains a description of the conditions in the workhouse at Ewhurst which is stated to be "illustrative of the scenes not infrequently presented to our Assistant Commissioners". The Commissioner found among other things that a third room was the sleeping place of a young woman affected with a certain loathsome disease, and in company with her were several boys and girls.

Some of the workhouses in larger towns had venereal wards. In the account of the workhouse in Birmingham in $1843^{3}$, it is stated that the nurse in the women's V.D. ward had an annual salary of $£ 8$, and that the attendant in the men's ward (one of the pauper inmates) had a gratuity of $1 s$. per week. The conditions of some of these wards can be imagined from a description given by Mr. F. Cooper, surgeon to the workhouse at Southampton, which was published in $1844^{4}$. He protested to the Board of Guardians that

the venereal ward also has double beds, in which two are placed in bed together ; and, although the apartment is not so crowded (as the general sick wards), it is yet utterly incompatible with propriety as well as health, that disease so obnoxious in itself, so virulent as I have seen it, should be brought into actual contact with a second party lying in the same bed, and exposed by continuent juxtaposition under the same covering 
to the offensive and purulent discharges which are generated by the various forms of the complaint under which the respective parties labour.

In other workhouses, persons suffering from venereal disease were placed in the general sick wards. The report of $1842^{5}$ contains an account from Mr. H. Hancock, surgeon to the Charing Cross Hospital, on the workhouse in Nottingham. Mr. Hancock complained about "the crowded and unhealthy state of the house " and mentioned that

among the 21 patients in the male sick ward, four were suffering from "syphilis, etc.", and from the eighteen patients in the female ward, five had rupia syphilis, etc.

Other patients in the wards were suffering from pneumonia, fever, diarrhoea, epilepsy, peritonitis, mammary abscess, paraplegia, and so on.

The Act of 1834 did not make any recommendations about the admission of sick poor people to the workhouses. From the middle of the century onwards it was realized that sick poor persons were having to be sent in increasing numbers to the workhouses, and the Poor Law Board circularized an order in $1868^{\circ}$ suggesting that every large workhouse should have wards for "venereal cases of both sexes". Other wards thought to be necessary, besides the ordinary sick wards, were wards for itch cases, for dirty and offensive cases, and for fever and smallpox.

During the 17th and 18th centuries lewd women had been sent to the House of Correction; in later periods prostitutes who for some reason or other had become destitute had to be admitted to the workhouse. Mr. H. G. Codd, who had investigated the poor law administration in the "western division of the metropolis" in great detail for the Royal Commission in 1834', quoted statements from various officials concerning the number of prostitutes admitted to the workhouses in that area. For example, the clerk to the Overseers of the Poor at St. James, Westminster, testified that

we have, both in the house and out of the house, many women receiving relief, who are known to be prostitutes ; those in the house are for the most part there in consequence of illness or disease.

The clerk of St. Margaret and St. John, Westminster, stated that many prostitutes had to be admitted to the workhouse " either from want or disease, or both ". He further stated

they walk the streets until reduced to great distress and then apply to be taken into the house ; they remain with us until their strength is recruited and then return to the former practice.

Complaints were frequently made about the bad influence of the prostitutes on young girls who were brought up in the workhouse and who could not be kept separate. The master of the workhouse at Greenwich for instance, expressed the opinion in $1841^{8}$ that

at least one third of the lowest and coarsest prostitutes of London have been brought up in the workhouses.

The conditions prevailing in some of the workhouses made it almost impossible to maintain discipline. The prostitutes in the workhouses in Stepney, Wapping, and other parts of East London seem to have been especially troublesome. Dr. J. P. Kay (one of the Assistant Commissioners), reporting in $1840^{\circ}$ on " the conduct of dissolute women in the workhouse ", stated that

this class of woman is universally found to be a source of demoralization and disorder, not merely in the workhouses of the metropolitan district, but in all workhouses not comprising a population solely rural.

He suggested that parliament should be asked to empower the magistrates to send those women whom he described as " this refuse of the prostitution in London"

for such a space of time, not exceeding one year, as they may see fit, to an establishment intended to accomplish their reformation.

One way of getting rid of troublesome prostitutes was to deport them overseas. Chadwick (1833), reporting on the condition of some of the workhouses in London, published the following statement from the governor of the workhouse at Lambeth :

We have perhaps from twenty to thirty prostitutes in the house. These, the worst characters, can always speak with the best characters, and the form of the house allows us no means of preventing it. Last October, as an experiment, we sent off eight girls to Van Diemen's land; they were all brought up as workhouse children and were incorrigible prostitutes.

In $1841^{10}$, the Guardians of St. Marylebone wanted " to send ten girls aged 16-26 to the colony of South Australia". The women were described as "a class of females who although they are not reduced to the very last stage of viciousness were still of the most abandoned disposition . . . a troublesome set of girls whom it is desirable to get rid of ". The plan, however, had to be dropped as the Poor Law Commissioners objected very strongly, mainly for moral reasons.

It was apparently a widespread practice to punish "disorderly and profligate women" by making them wear a yellow dress, and thus the female wards of the workhouses were called in slang "canary wards". In 1840 ", the Poor Law Commissioners deprecated the use of a "dress for unchaste women" and suggested that "women of infamous and thoroughly abandoned character" 
should be segregated. They explained that the separation should rest " not on the consideration of their past conduct but on that of their present habits and characters". In an order in $1841^{12}$, defining the disciplinary powers of the masters of the workhouses, they allowed, however, that

a dress different from that of the other inmates shall be worn by disorderly and refractory paupers during a period of not more than $\mathbf{4 8}$ hours.

Two instances are reported which show that the masters of the workhouses had occasionally to deal with women who wanted to leave the workhouse while still suffering from venereal disease in an infectious stage. In their report of $1843^{13}$, the Poor Law Commissioners stressed the necessity of obtaining uniformity regarding workhouse rules and of abolishing the so-called "local rules" some of which were very harsh. As an illustration, they mentioned a case which had been the cause of an interpellation in 1816 in the House of Commons. Sir Robert Heron (Hansard, 1816) reported that, when visiting a workhouse, he was told that

a young girl had been chained to the wall with a chain which weighed $28 \mathrm{lb}$. and that she had escaped with the chain. The reason for her confinement was that she was infected with a disorder which it was feared she might communicate to others.

In $1840^{14}$, the correspondence of the Poor Law Commissioners with the Boards of Guardians of the Richmond Union, Surrey, was published under the heading "Right of Diseased Paupers to leave the Workhouse". Correspondence of this type helped to define the policy of the Commissioners and could be used as a directive. The clerk to the Guardians had informed the Commissioners that a "woman labouring under severe venereal disease asked leave to quit the house for a short period". The master refused, but the woman left without permission; after three days she came back and asked to be admitted again. The clerk therefore enquired

whether it would be lawful to prevent a person leaving the house whilst labouring under any dangerous or infectious disease.

Mr. Chadwick pointed out in his answer, that the Poor Law Commissioners had received " numerous communications respecting the expediency of detaining in the workhouse persons who are in fact unable to maintain themselves". He went on to explain, in his stern manner, that

such short absences are used for a bad purpose by persons who, finding the temperance, cleanliness, and order of the workhouse irksome to them, wish to enjoy a short interval of riot and debauch-young women in particular are in the habit of leaving the workhouse in this manner for short periods, which, it is feared, are commonly employed by them for purposes of disorder, drunkenness, prostitution, and other mal-practices. ... The case stated differs from the ordinary cases only in the diseased state of the woman, and in the probability that if she were allowed to go out of the workhouse, she would damage her own health and communicate the disease to others. ... . If such a person being an adult and of sound mind, wishes to leave the workhouse, the Commissioners think that the officers have no power to detain him in it, ... and the Commissioners do not feel confident that they have under the present law, the means of enabling the guardians to make any distinction between these and ordinary cases-they are unwilling to issue such order without more unambiguous legislative authority.

This is typical of the harsh attitude of the Poor Law Commissioners. The "Kings of Somerset House ", as they used to be called, were known even in their own day for their lack of humanity, but it has to be noted that, in spite of their harshness, they opposed any tendencies to curtail personal liberty.

The Contagious Diseases Act of 1864 (27 and 28 Vict. c.85) provided the power to detain women suffering from venereal disease in certified hospitals, but these regulations could only be enforced in certain naval and military areas. As a result of the efforts of Mrs. Josephine Butler, who formed the "Ladies" National Association" in 1869 with the object of having the act repealed, it was suspended in 1883 , and finally repealed in 1886.

The Reports give no indication of the actual numbers of persons suffering from venereal disease who were admitted to the workhouses, nor do they give any information about their treatment. The references to the numbers of prostitutes in the workhouses have to be accepted with some caution. It is recognized nowadays that critics of social conditions in former times often tended to exaggerate. It would also be a serious mistake to regard the conditions of workhouses in the London area as typical of the rest of the country.

The quoted references illustrate a very sad chapter in the social history of venereal disease. This problem was regarded almost exclusively as a moral one, and a venereal infection was thought to be proof of the utmost depravity, especially in the female. In a previous paper (Fessler, 1949) an attempt was made to explain the change from the tolerant attitude of the 18th century towards venereal disease, to the intolerance of the 19th century by the changes in the socio-economic structure of the country. Because venereal disease was a "moral" problem, it was inevitable that society and the authorities should be strongly biased against the female sex when venereal disease 
began to be regarded as also a legal problem. Typical of the Victorian attitude, is the fact that the very words " venereal disease" were sometimes considered to be unprintable and had to be transcribed. The Act of 1864 (see above) which provided compulsory treatment for women was passed under the title "An Act for the Prevention of Contagious Diseases at certain Naval and Military Stations ". In the preamble it is explained that "The term "contagious disease" means venereal disease including gonorrhoea ". Unfortunately, for a long period, this discrimination between the sexes caused venereal infection in the male to be regarded as a tragedy, but in the female as a crime. Traces of this attitude, which could be found in every country and among all classes, persist even to this day.

\section{REFERENCES}

Chadwick, E. (1833). In " Extracts from the Information received by His Majesty's Commissioners as to the Administration and Operation of the Poor-Laws ", p. 242. Published by authority, Fellowes, London.

Fessler, A. (1949). British Journal of Venereal Diseases, 25,84 .

Heron, R. (1816). In Hansard, "The Parliamentary Debates ", vol 33, p. 185 . London.
Middleton, J. (1807). "View of the Agriculture of Middlesex ", p. 71. Board of Agriculture, London.

1 "Report from His Majesty's Commissioners for inquiring into the Administration and Practical Operation of the Poor Laws" (1834). Vol 38 (Appendix E), p. 41. London.

2 1st Annual Report of the Poor Law Commissioners (1835), p. 35.

3 9th Annual Report of the Poor Law Commissioners (1843), pp. 235-6.

4 10th Annual Report of the Poor Law Commissioners (1844), p. 166

5 8th Annual Report of the Poor Law Commissioners (1842), p. 206.

6 21st Annual Report of the Poor Law Board (1868), p. 47.

7 Report from His Majesty's Commissioners (1834). Vol 28 (Appendix A), p. 75.

87 th Annual Report of the Poor Law Commissioners (1841), p. 154.

9 6th Annual Report of the Poor Law Commissioners (1840), p. 287.

10 7th Annual Report of the Poor Law Commissioners (1841), pp. 253-6.

11 6th Annual Report of the Poor Law Commissioners (1840), p. 98.

127 th Annual Report of the Poor Law Commissioners (1841), p. 115.

13 9th Annual Report of the Poor Law Commissioners (1843), p. 242.

14 6th Annual Report of the Poor Law Commissioners (1840), p. 293. 